\title{
Cost-Effectiveness Analysis of Endovascular Coiling versus Neurosurgical Clipping for Intracranial Aneurysms in Republic of Korea
}

\author{
Hyuk Won Chang, MD', Shang Hun Shin, MD², Sang Hyun Suh, MD², \\ Bum-soo Kim, MD', Myung Ho Rho, MD
}

Purpose: The International Subarachnoid Aneurysm Trial (ISAT) revealed that in ruptured intracranial aneurysms (RA), endovascular coiling (EC) yields better clinical outcomes than neurosurgical clipping (NC) at 1 year. In unruptured aneurysms (UIA), EC is being increasingly used as an alternative to NC due to patients' preference. There is a lot of difference in treatment cost (EC vs. NC) between countries. There is one recently published study dealing with the comparative cost analysis only in UIAs in South Korea. But it is a hospital-based study. So, the authors performed a nation-wide cost effective comparison in our country.

Materials and Methods: This study was a retrospective analysis of healthcare big data open systems in Health Insurance Review \& Assessment Service (HIRA). Hospital cost data of the recent 5 years (from January 2010 to December 2014) were analyzed according to patients' age and sex and the presence of subarachnoid hemorrhage.

Results: When comparing the total hospital costs for NC of a UIA $(n=13,756)$ and EC of a UIA $(n=17,666)$, NC [mean \pm standard deviation (SD): $W 7,987,179 \pm 3,855,029]$ resulted in significantly lower total hospital costs than EC [ $W 10,201,645 \pm 5,001,626, p<0.0001]$, although a shorter hospital stay with EC of a UIA [ $8.6 \pm 7.4$ days] vs. NC [15.0 \pm 8.3 days, $p<0.0001]$. When comparing the total hospital costs for NC of a RA $(n=7,293)$ and EC of a RA $(n=6,954)$, NC $[W 13,914,993 \pm 6,247,914]$ resulted in significantly lower total hospital costs than EC $[W 16,702,446 \pm 7,841,141, p<0.0001]$, although shorter hospital stays for EC of a RA [19.8 \pm 11.4$]$ vs. NC [23.0 $\pm 10.3, p<0.0001]$.

\footnotetext{
'Department of Radiology, Keimyung University, School of Medicine \& Dongsan Medical Center, Daegu, Korea

${ }^{2}$ Department of Radiology, Ulsan University Hospital, University of Ulsan College of Medicine, Korea

${ }^{3}$ Department of Radiology, Gangnam Severance Hospital, Yonsei University College of Medicine, Seoul, Korea

${ }^{4}$ Department of Radiology, Seoul St. Mary's Hospital, The Catholic University of Korea, Seoul, Korea

${ }^{5}$ Department of Radiology, Kangbuk Samsung Hospital, Sungkyunkwan University College of Medicine, Seoul, Korea

Received July 19, 2016; accepted after revision August 10, 2016.

Correspondence to: Hyuk Won Chang, MD, Department of Radiology, Dongsan Medical Center, School of Medicine, Keimyung University, 194 Dongsan-dong, Jung-gu, Daegu 700-712, Korea.

Tel. 82.53.250.7770 Fax.82.53.250.7766 E-mail: hyukwonchang@korea.com

This is an Open Access article distributed under the terms of the Creative Commons Attribution Non-Commercial License (http://creativecommons.org/licenses/by-nc/3.0) which permits unrestricted non-commercial use, distribution, and reproduction in any medium, provided the original work is properly cited.
} 
Conclusion: The total hospital costs for the NC of both UIAs and RAs were found to be lower than those for EC in South Korea.

Key Words : Intracranial Aneurysm; Hospital Costs; Insurance; Health, Surgical Instruments; Subarachnoid Hemorrhage; Retrospective Studies

Even with the introduction of International Subarachnoid Aneurysm Trial (ISAT) data, the management of ruptured aneurysms (RA) is still a topic of debate $[1,2]$. And there is no prospective, randomized trial comparing endovascular coiling (EC) versus neurosurgical clipping (NC) for unruptured intracranial aneurysms (UIAs) that has yet been performed $[2,3]$. There are several studies dealing with cost analysis for the treatments of RAs and UIAs in the United States of America (USA), Canada, Europe and developing countries, but the results are very different among countries [4-11]. And there is one recently published study dealing with comparative cost analysis only for UIAs in South Korea [11]. But it is a hospital-based study. So, the authors performed a nation-wide cost effective comparison in our country.

\section{MATERIALS AND METHODS}

This study was a retrospective analysis of healthcare big data open systems in Health Insurance Review \& Assessment Service (HIRA) and was approved by the authors' Institutional Review Board. HIRA is a government-related organization that has created a proper claims review, and is the quality assessment system for national health insurance (NHI), the public medical insurance system operated by the Korean government [12-14]. The NHI program overviews a compulsory social insurance system covering the entire population. As each person has a unique resident registration number, we could exclude subject duplication. Given the database's high reliability, many epidemiological studies using the HIRA database have been published in scientific journals $[15,16]$.

HIRA adopts the widely-used International Classification of Diseases, 10th version (ICD-10), the most-recent version. Procedure coding is applied by the NHI reimbursement guidebook, published by HIRA [17].

\section{1) Preliminary data analysis}

EC is divided into assisted coiling (M1661/H261661) and other (simple) coiling (M1662/H261662) accord- ing to procedure complexity. Balloon-assisted coiling and stent-assisted coiling are both assisted coiling. NC is divided into simple clipping (S4641/H294641) and complex clipping (S4642/H294642). Complex clipping includes posterior circulation aneurysms, clipping with clinoidectomy, clipping with hematoma evacuation, clipping of fusiform, dissecting, mycotic, traumatic aneurysms and others with an irregular shape.

At first, we accessed the homepage of healthcare big data open systems in Health Insurance Review \& Assessment Service (HIRA) and investigated the whole hospital cost and procedure number of EC or NC from January 2010 to December 2015 [18].

On that homepage, we examined procedure code name during a specific period (from January 2010 to December 2015), which showed the procedure number and total hospital cost related to the procedure automatically.

\section{2) Detailed data analysis regarding the presence of subarachnoid hemorrhage}

We requested the person in charge of healthcare big data open systems in Health Insurance Review \& Assessment Service (HIRA) to collect all the hospitalized bills for patients over 30 years old with a UIA (I67.1) or subarachnoid hemorrhage (I60) who received simple NC (H294641), complicated NC (H294642), assisted EC (H261661) or simple EC (H261662). Hospital cost data of the recent 5 years (from January 2010 to December 2014) was analyzed according to patients' age, sex and the presence of hemorrhage. Hospital cost data were examined. Statistical analyses were performed using an Statistical Analysis Software (SAS) Enterprise Guide, version 6.1 (SAS Institute Inc., Cary, NC, USA). A $x^{2}$ test was used for comparison of categorical variables and an independent t-test was used for comparison of continuous variables. The correlation of continuous variables was assessed using a Pearson correlation analysis. The results were considered significant for probability values less than 0.05 . 


\section{Hyuk Won Chang, et al.}

\section{RESULTS}

\section{1) Preliminary data analysis}

The annual number of EC from 2010 to 2015 was $4,657,5,370,5,760,6,506,7,295$ and 7,555, respectively and the average annual increasing rate was $10.24 \%$. And that of NC was 5,546, 5,910, 5,887, $5,393,5,758$ and 5,503, respectively and the average annual increasing rate was $0.02 \%$ (Fig. 1).

The total hospital cost of EC in South Korea from 2010 to 2015 was $W 4,387,944,000,5,761,911,000$, $6,988,279,000,8,233,594,000,10,181,170,000$, $12,639,405,000$, respectively and the average annual increasing rate of cost was $23.64 \%$. And that of $\mathrm{NC}$ in South Korea from 2010 to 2015 was W10,226,634,000, $10,795,875,000,10,897,109,000,10,144,470,000$, $12,510,628,000,16,178,967,000$, respectively and the average annual increasing rate of cost was $10.45 \%$ (Fig. 2).

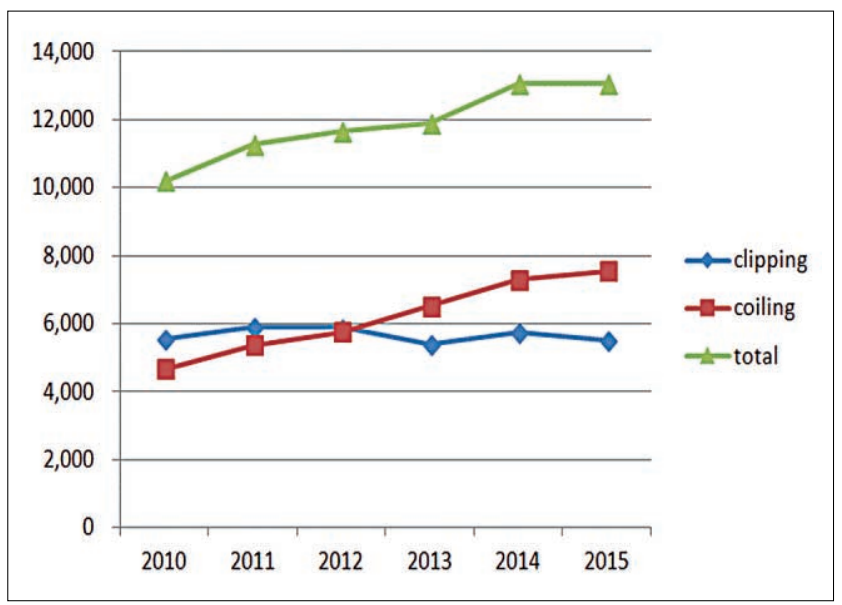

Fig. 1. Annual number of coiling and clipping in South Korea

\section{2) Detailed data analysis regarding the presence of subarachnoid hemorrhage}

Patients with aneurysm without subarachnoid hemorrhage $(n=31422)$

$\mathrm{NC}$ was done in 13756 patients and $\mathrm{EC}$ was done in 17666. Coiling was much more frequently performed in females and the elderly. NC [mean \pm standard deviation (SD): $W 7,987,179 \pm 3,855,029]$ resulted in significantly lower total hospital costs than EC [W10,201,645 $\pm 5,001,626 \mathrm{p}<0.0001]$, although there were shorter hospital stays for EC of a UIA [8.6 \pm 7.4 days $]$ vs. NC [15.0 \pm 8.3 days $]$ (Table 1 ).

Patients with an aneurysm with subarachnoid hemorrhage $(n=14247)$

$\mathrm{NC}$ was done in 7293 patients and $\mathrm{EC}$ was done in 6954. EC was much more frequently performed in females and the elderly. NC [W 13,914,993 \pm $6,247,914]$ resulted in significantly lower total hospital costs than EC [W16,702,446 $\pm 7,841,141 \mathrm{p}<0.0001]$, although there were shorter hospital stays for EC of a RA [19.8 \pm 11.4$]$ vs. NC [23.0 \pm 10.3$]$ (Table 2).

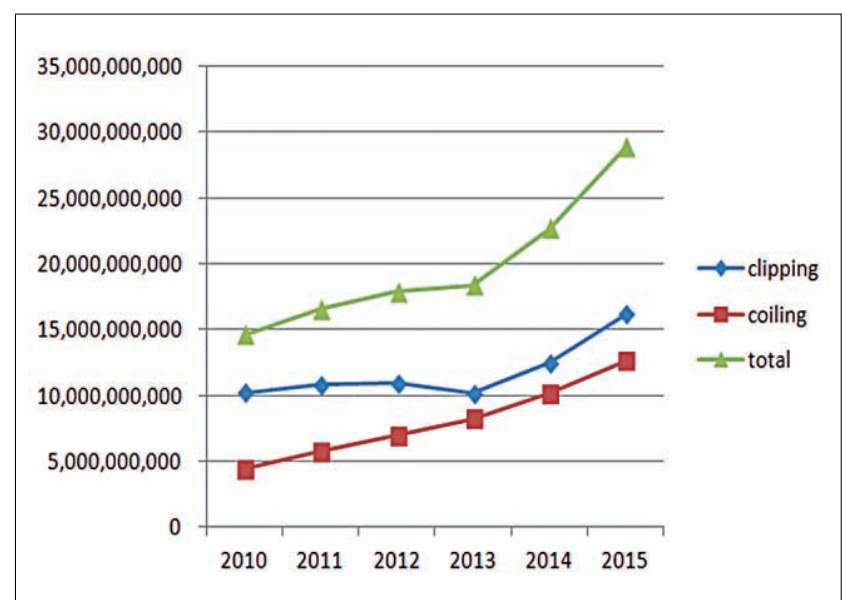

Fig. 2. Annual total hospital cost of coiling and clipping in South Korea $(1=W 1,000)$

Table 1. Charateristics of Unruptured Intracranial Aneurysms

\begin{tabular}{lccc}
\hline & & UIA $(\mathrm{n}=31,422)$ & $\mathrm{p}$-value \\
\cline { 2 - 4 } & Clipping & Coiling & $<$ \\
\hline Number & 13,756 & 17,666 & $<0.0001$ \\
Sex, female (\%) & $9,425(68.5)$ & $59.0 \pm 10.8$ & $<0.0001$ \\
Age (years) & $58.0 \pm 9.6$ & $10,201,645 \pm 5,001,626$ & $<0.0001$ \\
Total hospital cost (W) & $7,987,179 \pm 3,855,029$ & $<.6 \pm 7.4$ & $<0.0001$ \\
\hline Hospital stay (days) & $15.0 \pm 8.3$ & & \\
\hline
\end{tabular}




\section{Cost-Effectiveness Analysis of Aneurysm Treatment}

\section{DISCUSSION}

This is the first nationwide study to assess the effectiveness of EC and $\mathrm{NC}$ for intracranial aneurysms at hospital discharge for the Korean population database. It is well known that hospital costs of both $\mathrm{EC}$ and $\mathrm{NC}$ are very different among countries due to diverse national medical systems and prices of medical devices [5-9].

For the first time, Bairstow et al. compared hospital costs for 22 ISAT patients (10 EC, $12 \mathrm{NC}$ ) enrolled at 2 hospitals in Australia [10]. They found that hospital costs were lower for the EC group than the NC group because of lower staffing costs and lower costs of postprocedure hospitalization, despite expensive EC procedure consumables (Table 1).

In Canada, Javadpour et al. studied hospital costs for
62 ISAT patients ( $30 \mathrm{EC}, 32 \mathrm{NC})$ at their institution, and the result is somewhat different from Australia's result [4]. They revealed no significant difference in cost between the EC and NC group. The benefit of a shorter length of hospitalization in the EC group was offset by the higher procedure costs of EC.

In the United Kingdom, Wolstenholme et al reported hospital costs for $\mathrm{EC}(\mathrm{n}=809)$ and $\mathrm{NC}(\mathrm{n}=835)$ in 42 ISAT centers [5]. They found that the EC group initially had lower hospital costs than the NC group, which was associated with a shorter length of hospitalization for the initial procedure. However, this was offset by higher costs for the EC group for subsequent procedures, angiograms, complications, and adverse events in the subsequent 12- to 24-month period.

In the Netherlands, Halkes et al. reported a comparison of costs for EC $(n=23)$ and $\mathrm{NC}(\mathrm{n}=23)$ in patients with UIAs treated at their institution, and found that, on

Table 2. Charateristics of Ruptured Intracranial Aneurysms

\begin{tabular}{lccc}
\hline & & $R A(n=14,247)$ & $p$-value \\
\cline { 2 - 4 } & Clipping & Coiling & $<, 954$ \\
\hline Number & 7,293 & $4,558(65.55)$ & $<0.0001$ \\
Age (years) & $4,496(61.7)$ & $57.4 \pm 13.1$ & $<0.0001$ \\
Total hospital cost (W) & $55.4 \pm 11.9$ & $16,702,446 \pm 7,841,141$ & $<0.0001$ \\
Hospital stay (days) & $13,914,993 \pm 6,247,914$ & $19.8 \pm 11.4$ & $<0.0001$ \\
\hline
\end{tabular}

Table 3. Published Studies of Cost-effectiveness Analysis for Endovascular Versus Neurosurgical Treatment of Intracranial Aneurysms

\begin{tabular}{|c|c|c|c|c|c|c|}
\hline No. & Author, year & Country, study year & Design, case no. (NC, EC) & An. type & Results & Detail \\
\hline 1 & Bairstow et al (10), 2002 & Australia, 1999 & Hospital $(12,10)$ & RA & $\mathrm{NC}>\mathrm{EC}$ & ISAT pts \\
\hline 2 & Javadpour et al (4), 2005 & Canada, 1998-2002 & Hospital $(32,10)$ & RA & $\mathrm{NC} \approx \mathrm{EC}$ & ISAT pts \\
\hline 3 & Wolstenholme et al (5), 2008 & UK, 1997-2002 & National $(835,809)$ & RA & $\mathrm{NC} \approx \mathrm{EC}$ & ISAT pts \\
\hline 4 & Halkes et al (18), 2006 & the Netherlands, $1997-2003$ & Hospital $(23,23)$ & UIA & $\mathrm{NC}<\mathrm{EC}$ & \\
\hline 5 & Higashida et al (7), 2007 & US, $1998-2000$ & National $(1881,654)$ & UIA & $\mathrm{NC}>\mathrm{EC}$ & \\
\hline 6 & Zubair et al (9), 2009 & Pakistan, 2004-2007 & Hospital $(25,18)$ & RA & $\mathrm{NC}<\mathrm{EC}$ & \\
\hline 7 & Hoh et al (19), 2010 & US, 2002-2006 & National $(6019,3616)$ & Both & $\mathrm{NC}>\mathrm{EC}$ & \\
\hline 8 & Hoh et al (20), 2009 & US, 2005-2007 & Hospital $(306,259)$ & Both & $\mathrm{NC}<\mathrm{EC}$ & \\
\hline 9 & Maud et al (6), 2009 & US (ISAT data), 2005-2006 & International $(1070,1073)$ & RA & $\mathrm{NC}<\mathrm{EC}$ & ISAT pts \\
\hline 10 & Duan et al (8), 2015 & US, 2010-2012 & Hospital $(69,56)$ & RA & $\mathrm{NC}<\mathrm{EC}$ & \\
\hline 11 & Kim et al (11), 2015 & S. Korea, 2011-2014 & Hospital $(188,188)$ & UIA & $\mathrm{NC}<\mathrm{EC}$ & \\
\hline 12 & Current study & S. Korea, 2010-2014 & National $(21049,24620)$ & Both & $\mathrm{NC}<\mathrm{EC}$ & \\
\hline
\end{tabular}

Abbreviations: An.: aneurysm; NC: neurosurgical clipping; EC: endovascular coiling; ISAT: International Subarachnoid Aneurysm Trial; pts: patients; RA: ruptured aneurysm; UIA: unruptured intracranial aneurysm 


\section{Hyuk Won Chang, et al.}

average, the total cost of EC was higher than that for NC. Although NC had higher costs related to the need for intensive care facilities and a longer length of hospitalization, this was more than offset by the higher material cost of EC [19].

In United States of America (USA), Higashida et al performed a nationwide study of the costs of EC $(n=654)$ and $\mathrm{NC}(\mathrm{n}=1881)$ in patients with UIAs treated between 1998 to 2000, and found that the total cost of EC was lower than that for NC. And EC was associated with fewer adverse outcomes, decreased mortality and shorter lengths of stay [7]. It is the first USA study to access the effectiveness of both EC and NC. After that, there were several studies dealing with this topic, but they are not consistent.

Hoh et al reported a nationwide comparison of costs of EC and NC in patients with RAs (3616 EC, 6019 NC) and UIAs (4699 EC, $4700 \mathrm{NC}$ ) treated in the USA (between 2002 to 2006), and found that the total cost of $\mathrm{EC}$ was lower than that for NC for both RAs and UIAs [20].

But, Hoh et al reported a different result according to their hospital data. They compare costs of EC and NC in patients with RAs (98 EC, $100 \mathrm{NC}$ ) and UIAs (161 EC, $206 \mathrm{NC}$ ) treated at the University of Florida, USA (between 2005 to 2007), and found that the total cost of $\mathrm{EC}$ was higher than that for NC for both RAs and UIAs [21].

Maud et al. performed a cost-effective analysis using a somewhat different method [6]. They obtained clinical data from ISAT and analyzed costs for their country's database (USA). They compared EC $(n=1073)$ and $\mathrm{NC}(\mathrm{n}=1070)$ and found that EC is more costly but is associated with better outcomes than $\mathrm{NC}$ at 1 year after the procedure.

Duan et al reported comparison of costs of $\mathrm{EC}(\mathrm{n}=56)$ and $\mathrm{NC}(\mathrm{n}=69)$ in patients with UIAs treated at their institution in the USA (between 2010 to 2012), and revealed that the total cost of EC was higher than that for $\mathrm{NC}$ and the cost of coils and devices was the predominant contributor to the higher total costs of EC [8].

In Pakistan, Zubair et al reported a comparison of costs of $\mathrm{EC}(\mathrm{n}=18)$ and $\mathrm{NC}(\mathrm{n}=25)$ in prospectively collected patients with RAs treated at their institution and found that the total cost of EC was higher than that for NC. The benefits of apparent decrease in length of stay in the EC group were offset by higher procedure prices and the cost of consumables [9].

In South Korea, a previous study done by Kim et al reveals that total hospital costs of $\mathrm{EC}$ is higher than $\mathrm{NC}$ in UIA [11].

Thus, the hospital costs of both EC and NC are very different among countries. And furthermore, even in one country, these trends change as time goes on, as seen in the USA (gray boxes in Table 1).

As shown in our preliminary data analysis, the average annual increasing rate of EC was $10.24 \%$ and that of $\mathrm{NC}$ was $0.02 \%$. From 2013 to 2015 , there is some decrease in cases of $\mathrm{NC}$, which is not a surprising finding that the USA experienced since 2005 [22].

And hospital costs of both EC and NC are dramatically rising.

Our study reveals that cost of EC is much higher than that of NC in both UIA and RA, even though there is a shorter hospital stay of EC for both RA and UIA.

In South Korea, the procedure cost of simple clipping (S4641) and complex clipping (S4642) are W2111400 and 2392820, respectively. And that of assisted coiling (M1661) and simple coiling (M1662) are W1261800 and 1195860 respectively. Thus, the procedure cost of $\mathrm{NC}$ is much higher than that of EC.

So, the cause of the high cost of EC is not hospitalization cost, but is due to the cost of medical devices as other authors mentioned [8-10, 19].

At this point, we have to remind ourselves of our senior's advice regarding new technology and our physicians' insight [23, 24].

Our study has many limitations. First, it is a retrospective study without randomization. Second, it is from only the discharge bill data after each respective treatment, and longer-term economic impact data was not available. Third, ICD-10 coding cannot identify the size and location of cerebral aneurysms, so we can't analyze correlation between hospital cost and cerebral aneurysm characteristics. Fourth, it was not possible to identify procedural failures or complication rates.

\section{CONCLUSION}

The total hospital costs for NC of both UIAs and RAs were found to be lower than those for EC in South Korea.

\section{Acknowledgement}

This study was supported by a Korean Society of Interventional Neuroradiology (KSIN) research grant.

\section{References}

1. Molyneux A, Kerr R, Stratton I, Sandercock P, Clarke M, Shrimpton J, et al. International Subarachnoid Aneurysm Trial 


\section{Cost-Effectiveness Analysis of Aneurysm Treatment}

(ISAT) of neurosurgical clipping versus endovascular coiling in 2143 patients with ruptured intracranial aneurysms: a randomised trial. The Lancet 2002;360:1267-1274

2. Jeong HW, Seo JH, Kim ST, Jung CK, Suh SI. Clinical practice guideline for the management of intracranial aneurysms. Neurointervention 2014;9:63-71

3. Thompson BG, Brown RD Jr, Amin-Hanjani S, Broderick JP, Cockroft KM, Connolly ES Jr, et al. Guidelines for the Management of Patients With Unruptured Intracranial Aneurysms A Guideline for Healthcare Professionals From the American Heart Association/ American Stroke Association. Stroke 2015;46:2368-2400

4. Javadpour M, Jain H, Wallace MC, Willinsky RA, ter Brugge KG and Tymianski M. Analysis of cost related to clinical and angiographic outcomes of aneurysm patients enrolled in the international subarachnoid aneurysm trial in a North American setting. Neurosurgery 2005;56:886-894

5. Wolstenholme J, Rivero-Arias O, Gray A, Molyneux AJ, Kerr RS, Yarnold JA, Sneade M and Group ISATC. Treatment pathways, resource use, and costs of endovascular coiling versus surgical clipping after aSAH. Stroke 2008;39:111-119

6. Maud A, Lakshminarayan K, Suri MFK, Vazquez G, Lanzino G and Qureshi AI. Cost-effectiveness analysis of endovascular versus neurosurgical treatment for ruptured intracranial aneurysms in the United States. J Neurosurg 2009;110:880

7. Higashida RT, Lahue BJ, Torbey MT, Hopkins LN, Leip E and Hanley DF. Treatment of unruptured intracranial aneurysms: a nationwide assessment of effectiveness. AJNR Am J Neuroradiol 2007;28:146-151

8. Duan Y, Blackham K, Nelson J, Selman W and Bambakidis N. Analysis of short-term total hospital costs and current primary cost drivers of coiling versus clipping for unruptured intracranial aneurysms. J Neurointerv Surg 2015;7:614-618

9. Zubair Tahir TM, Enam SA, Pervez Ali AR, Bhatti A, ul Hag T. Cost-effectiveness of clipping vs coiling of intracranial aneurysms after subarachnoid hemorrhage in a developing country--a prospective study. Surg Neurol 2009;72:355-360

10. Bairstow P, Dodgson A, Linto J and Khangure M. Comparison of cost and outcome of endovascular and neurosurgical procedures in the treatment of ruptured intracranial aneurysms. Australas Radiol 2002;46:249-251

11. Kim M, Park J and Lee J. Comparative Cost Analysis for Surgical and Endovascular Treatment of Unruptured Intracranial Aneurysms in South Korea. J Korean Neurosurg Soc 2015;57:
455-459

12. Kim DS. Introduction: health of the health care system in Korea. Soc Work Public Health 2010;25:127-141

13. Kim D. Special issue on the national health care system of South Korea. Soc Work Public Health 2010;25:125

14. Gjonbrataj J, Choi WI, Bahn YE, Rho BH, Lee JJ, Lee CW. Incidence of idiopathic pulmonary fibrosis in Korea based on the 2011 ATS/ERS/JRS/ALAT statement. Int J Tuberc Lung Dis 2015;19:742-746

15. Jee SH, Sull JW, Park J, Lee SY, Ohrr H, Guallar E, et al. Bodymass index and mortality in Korean men and women. $N$ Engl $J$ Med 2006;355:779-787

16. Lee CH, Kim K, Hyun MK, Jang EJ, Lee NR and Yim JJ. Use of inhaled corticosteroids and the risk of tuberculosis. Thorax 2013;68:1105-1113

17. Health insurance review and assessment service (HIRA) e-book. http://www.hira.or.kr/ebook/feb7fcf3-8e18-4d26-af6d-6db8b0123 ea4/453.html (accessed in Feb-27th-2016)

18. Healthcare big data open systems in Health Insurance Review \& Assessment Service. http://opendata.hira.or.kr/home.do (accessed in Feb-27th-2016)

19. Halkes PH, Wermer MJ, Rinkel GJ and Buskens E. Direct costs of surgical clipping and endovascular coiling of unruptured intracranial aneurysms. Cerebrovasc Dis 2006;22:40-45

20. Hoh BL, Chi YY, Lawson MF, Mocco J and Barker FG. Length of stay and total hospital charges of clipping versus coiling for ruptured and unruptured adult cerebral aneurysms in the Nationwide Inpatient Sample database 2002 to 2006. Stroke 2010; 41:337-342

21. Hoh BL, Chi Y-Y, Dermott MA, Lipori PJ and Lewis SB. The effect of coiling versus clipping of ruptured and unruptured cerebral aneurysms on length of stay, hospital cost, hospital reimbursement, and surgeon reimbursement at the university of Florida. Neurosurgery 2009;64:614-621

22. Huang MC, Baaj AA, Downes K, Youssef AS, Sauvageau E, van Loveren HR and Agazzi S. Paradoxical Trends in the Management of Unruptured Cerebral Aneurysms in the United States Analysis of Nationwide Database Over a 10-Year Period. Stroke 2011;42:1730-1735

23. Cloft HJ. Coils and cash: what coil vendors don't want you to know. AJNR Am J Neuroradiol 2009;30:1276-1277

24. Cloft HJ. What is all of the hype about? AJNR Am J Neuroradiol 2008;29:1604 